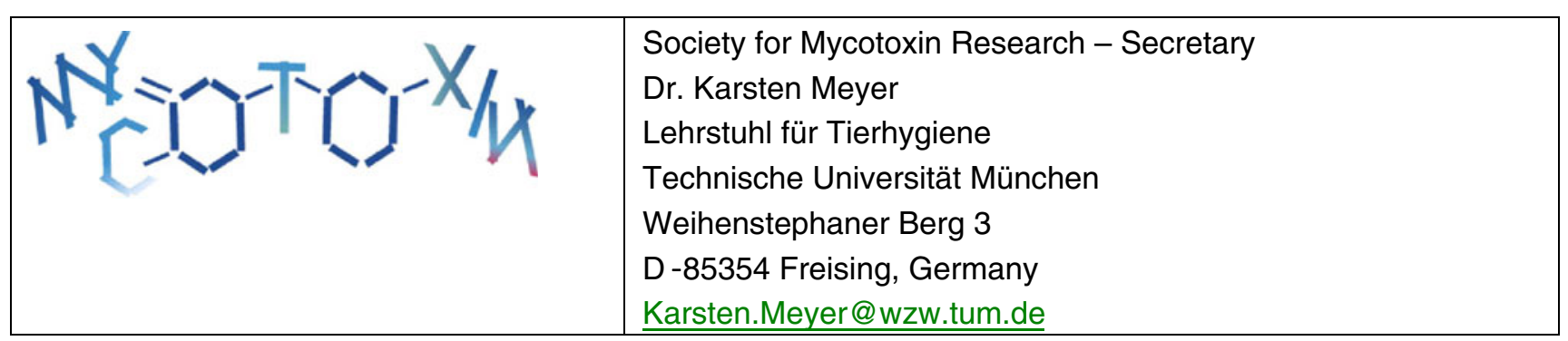

Published online: 15 December 2011

(C) Society for Mycotoxin Research and Springer 2011

\section{Brigitte Gedek Science Award 2012 for Mycotoxin Research}

The Society for Mycotoxin Research is pleased to announce this science award sponsored by Professor Dr. rer. nat. Brigitte Gedek, Ismaning, Germany. The award is endowed with

$$
\text { 10,000 Euro }
$$

with the intention to promote scientific research in mycotoxinology. The award will be granted for the seventh time during the 34th Mycotoxin Workshop (14-16 May 2012 in Braunschweig, Germany) by the Society for Mycotoxin Research (http://www.mycotoxin.de).

The award will be given to a scientist or a group of scientists for creative and outstanding achievements in the field of mycotoxin research. Eligible for consideration are (1) individual scientific contributions (masters thesis, doctoral thesis, or equivalent), as well as (2) publications in international scientific journals. Routine work in education and scientific management, as well as cumulative research work, will not be considered. Publications which have already received an award, or research work done in the fields of veterinary and medical mycology, are also not eligible for this award.

The award winner is selected by the Science Award Committee. Applications must be submitted via a member of the Society for Mycotoxin Research by mail to:

President: Society for Mycotoxin Research

Prof. Dr. Hans-Ulrich Humpf

Institute of Food Chemistry, Westfälische Wilhelms-

University Münster

Corrensstrasse 45, D-48149 Münster, Germany

\section{Deadline for applications is 1 March 2012.}

The necessary documents for application (one original and two copies each) are (1) a Curriculum Vitae of the candidate, (2) the scientific research publication submitted for consideration, and (3) a letter describing the scientific merit of this research work, signed by the member of the Society who submits the application. Interested scientists may contact by email the Secretary of the Society (Karsten. Meyer@wzw.tum.de) for enquiries concerning details of the application procedure.

The Society for Mycotoxin Research was founded in Munich (Germany) in 1997. The aim of this registered, non-profit international association is to promote research on all scientific fields of mycotoxin research. One of the core ideas was to create bridges between the different scientific disciplines working on the field of toxigenic fungi and mycotoxins. For membership enquiries, please contact the Secretary of the Society. Visit us also at www.mycotoxin.de. The Society co-organizes and sponsors the annual conference called "Mycotoxin Workshop", which dates back to 1978. The Society publishes its official journal, "Mycotoxin Research" together with Springer, Heidelberg. The Society biennially gives the Brigitte Gedek Science Award, which is the most prestigious award in the field of natural toxin research. The previous laureates were: 2000 Michael Gekle (Germany); 2002 Eckhardt Johanning (USA) and Uwe Lauber (Germany); 2004 Karsten Meyer (Germany) and Kristian Fog Nielsen (Denmark); 2006 Franz Berthiller (Austria); 2008 Wageha Awad (Austria) and Markus Schmidt-Heydt (Germany); 2010 Nicole Schütze, Irina Lehmann, Ulrike Bönisch, Jan C. Simon, and Tobias Polte (Germany). 